\section{Future looks rosy for UK}

BRITISH X-ray astronomy, it seems, is basking in a ray of sunshine, whatever clouds may be gathering over the Science and Engineering Research Council (SERC, see Nature 4 May, p.5) that supports the subject. Exosat, the European Space Agency's X-ray observatory, is just beginning operation in orbit, while almost simultaneously it appears that SERC has agreed to commit a sum "substantially less than $£ 10$ million" to yet another X-ray satellite, the German-led trilateral Rosat. The third partner to the DM300 million ( $£ 75$ million) satellite will be the United States. Rosat is due for launch on space shuttle number 60 in July 1987.

Dr Joachim Trumper, director of the Max Planck Institute for Extraterrestrial Physics in Garching that designed and is building Rosat, says Rosat is two to three times cheaper than had it been built and launched by ESA and is tremendous value.

Within six months of launch, it will have surveyed the X-ray sky at 1,000 times the sensitivity of the previous whole-sky map (by UHURU) and will then "with luck" perform one to two years of observations on selected objects. Rosat will increase the number of known $\mathrm{X}$-ray sources by a factor of 50, Trumper believes, and will have five times greater sensitivity for quasars than even the biggest ground-based optical telescopes.

Meanwhile, Exosat remains the only X-ray observatory aloft. European Space Agency scientist Brian Taylor, holding the first, hour-old Exosat maps of X-ray source Cygnus X-1, said on Monday that Exosat "looks healthy and is working", One proportional counter on one of two identical telescopes had failed and would be switched off "for some considerable time" until the ground staff could determine what was wrong, but other instruments had shown cosmic radiation backgrounds an order of magnitude lower than had been feared, "extremely low and extremely steady", contradicting early Apollo estimates, said Taylor

Exosat is three times smaller in focal length - and hence spatial resolution (colour) - than the Einstein observatory and has a smaller collecting area, but is better than Einstein in spectral resolution and in the observation of shorter wavelengths.

Exosat also has a remarkable orbit - out beyond the radiation belts (hence the fears about cosmic rays) to perigee at 191,000 km, compared with Einstein's circular 450-km orbit. This is an historical relic: Exosat was planned well before Einstein, when imaging X-ray telescopes were poor at best and observations were made by collimation. At that time astronomers envisaged locating $\mathrm{X}$-ray sources by lunar occultation, for which an eccentric orbit gave a large apparent motion of the Moon, thus covering some 20 per cent of the sky with possible occultations. In the event, occultation will hardly be necessary.

But the long orbit will still be useful: the satellite will be controllable in real time, remaining above the radiation belts for some 80 hours on each orbit, thus enabling rapid response to $\mathrm{X}$-ray flares - and to the unexpected.

Robert Walgate

\section{Lüst for ESA}

\section{Munich}

Professor Reimar Lüst, president of the élite German research organization the Max-Planck-Gesellschaft (MPG) for the past 12 years, is to be the next directorgeneral of the European Space Agency (ESA). He hopes to convince reluctant member states that ESA's mandatory science budget should be bigger.

Lüst conveys a diplomatic and gentlemanly manner, but this merely conceals the "dynamic" man beneath, his German colleagues say. Sir Hermann Bondi, who was director-general of the European Space Research Organization when Lüst was its scientific director (1962-64), thinks Lüst will be an outstanding director-general.

Liist is a naval man: in 1943, at the age of 20 , he was shot out of a U-boat in the Atlantic and picked up by a British ship. He learned his physics in an American prisoner-of-war camp. He likens ESA's membership to a convoy: it cannot move faster than the slowest ship and cannot turn faster than the biggest.

It is clear, he says, that "the scientific demand in Europe is much greater than ESA can provide". He hopes that governments will see this.

ESA research satellites are not unduly expensive, he believes - although leading space researchers within the MPG say they can be two or three times the cost of launches outside the agency. "I can't confirm the figure", says Lüst. A fter all, "the same industries build the satellites". But Lüst is "interested to look into this". As for the failures of A riane, he argues these were just development problems. On communications satellites, where a commercial battle rages in Europe, ESA "must formulate a balance" between small and large states, he says. The objective of ESA is "the technological development of Europe ... my main priority is to have a coherent programme in research and application".

One little problem he will face when he moves to Paris to take up his job in July next year is that he does not speak a word of French. "My scientific language is $\mathrm{BE}$ broken English" he says. He believes that in science and technology "we should speak English, and not French and not German" - not an attitude that will go down too well in proud France. However, he promises to attend a few French lessons. Robert Walgate
EEC research

\section{Commission set to push ahead}

\section{Stuttgart}

EURGPEAN Community government leaders at their summit meeting in Stuttgart again failed to discuss the philosophy behind Community Research Commissioner Etienne Davignon's plans to revitalize Europe's research efforts in the face of stiff competition from Japan and the United States. But the fact that the summit communiqué made only a passing reference to joint research and development activities is unlikely to keep Davignon from pushing ahead with his ambitious new industry-oriented research strategy.

The subject was covered in just one paragraph of the communiqué, which reiterated the government leaders "determination to develop and make more effective Community action in research, innovation and the new technologies with a view to facilitating cooperation between enterprises". There was also a suggestion that the Commission should come up with ideas for "improving the international competitiveness of enterprises". So at least some of Davignon's ideas found their way into the communiqué, and the Commission can now feel free to devise concrete proposals for encouraging the development of biotechnology and telecommunications at a European level.

The first fruits of the Commission's philosophy on research are to be seen in Esprit, the European Strategic Programme for Research and Development of Information Technologies (see Nature 9 June, p.461). Pilot phase contracts are now being signed between the European Commission and various European research units.

But for Davignon and the Commission, joint research is only the beginning. The long-term aim is much closer industrial cooperation in areas such as telecommunications where the costs of developing sophisticated new systems are becoming too great for individual countries to bear. What is needed, Davignon states, is "a gradual transfer of powers and means from member states to the European Community institutions",

Davignon knows, however, that it is too early to come up with operational ideas for the European Community to take over some of the roles of the national telecommunications administrations. Governments are increasingly unwilling to give up national powers. So Davignon has asked European Community leaders to appoint a panel of senior officials "who would be able to commit their governments" on the issue. The panel would discuss such matters as how strategic technological options could be decided at Community level, how European industry could cooperate on precompetitive research and development and how a free choice of suppliers 
best be ensured.

The panel, which ideally should come up with preliminary conclusions before the end of the year, would also look into possibilities of setting up a European telecommunications body, placed under Commission authority. Commission sources admitted the ideas were given "a lukewarm reception" by Community governments.

Better received, and less radical, were Davignon's ideas on biotechnology. Davignon pleads for an extension of the 1982 programme, which was focused on agriculture and food, to the health sector. Research would again be equally financed by the Commission and by European industry.

But Davignon's ideas once again exceed the narrow framework of research and development. For Davignon, industry's access to raw materials must be improved. But Community governments are unlikely to follow Davignon on this point: opening up the market to imports of cheap farm produce like starch, a basic requirement of the biotechnology industry, would upset the already fragile and politically sensitive Common Agricultural Policy.

Geert Linnebank

\section{Europe and US to fuse on fusion?}

\section{Brussels}

THE European Commission wants to develop transatlantic cooperation in research on thermonuclear fusion and has asked member states for permission to negotiate a formal cooperation agreement with the US Administration.

A spokesman for the Commission said the US authorities had welcomed plans to exchange information and staff working on tokamak confinement vessels, alternative magnetic confinement technologies and inertial technology.

The idea of this cooperation was first launched on the eve of the Versailles Western economic summit in talks between Research Commissioner Etienne Davignon and President Reagan's scientific adviser, George Keyworth. A tentative agreement to institutionalize it was reached in March, but Community member states have yet to endorse the plan.

Europe currently leads the field in research on fusion reactors based on the magnetic plasma confinement principle, generally thought to be the most promising approach. Approximately 90 per cent of Europe's fusion research resources are invested in the development of the Culhambased Joint European Torus (JET) giant tokamak, which is expected to become operational later this year, and related projects. But Europe lags behind the United States in alternative technologies and fuel (tritium) handling.

Geert Linnebank

\section{Polychlorinated biphenyls in human tissue}

A REPORT published recently by the US Environmental Protection Agency on the levels of polychlorinated biphenyls (PCBs) in human adipose tissue shows that while almost all Americans now have detectable levels of the compounds in their tissues, very few have above the 3 parts per million (p.p.m.) level arbitrarily designated by the report as "high". The figure clearly shows the impact of the regulatory legislation that was introduced in 1976 controlling the "manufacture, processing or distribution" of PCBs. Before this date the number of people with "high" levels had been steadily increasing, but since 1976 this level has dropped dramatically so that now only one per cent of Americans have PCB levels above 3 p.p.m.

The report lists two caveats - first that the survey was conducted on cadavers which may not be representative of the general population, and second that only urban populations were investigated. Since much of the controversy over PCBs has involved their inclusion in herbicides this second proviso may mark a significant shortcoming.

The increase in background levels of $P C B$ in adipose tissue, and, to a lesser extent, in human milk, is due at least partly to their use in electrical equipment, chlorinated hydrocarbons being used as a dielectric in transformers and capacitors.

Dr F. Kutz, head of the field department on whose data the report was based, believes that "as a result of certain exemptions from the 1976 Toxic Substance Control Act around 600 million pounds of PCBs are still in existence, either in storage or in electrical appliances".

Melanie Kee

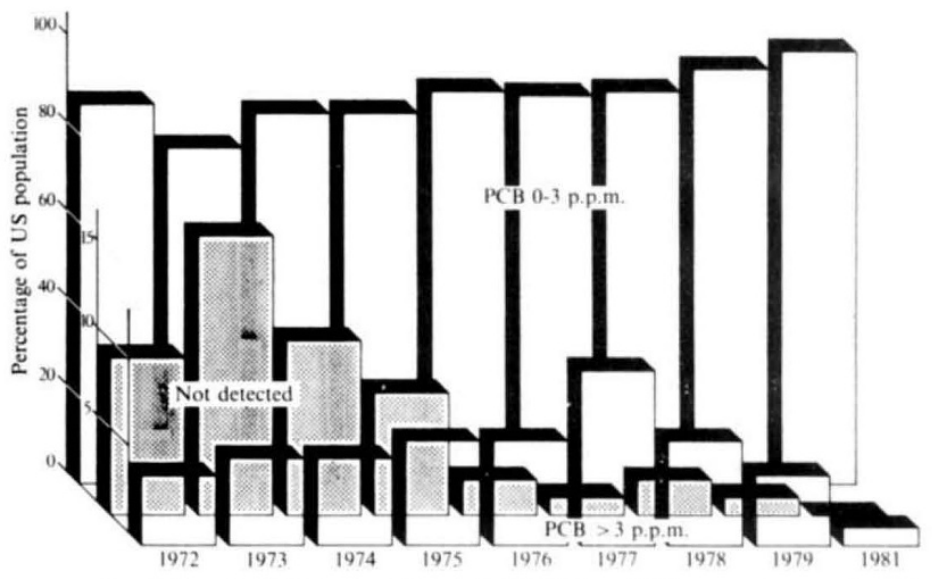

\section{Czechoslovakia}

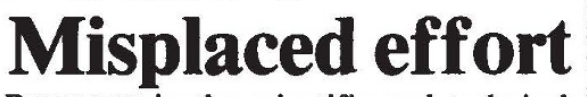

PROGRESS in the scientific and technical development of the country was reviewed in last week's meeting of the Communist Party of Czechoslovakia. The official report, delivered by Presidium member Milos Jakes, painted a gloomy picture, the "key problem" being the "slow and inadequate" implementation of research results in practice. Shortly before the meeting, however, the party daily Rude Pravo had come up with a new explanation of the lag - inefficient deployment of funds.

According to Rude Pravo, the excuse most often proffered by industrial enterprises failing to innovate is that of insufficient funds. However, it went on, a recent survey by the finance ministry had found that some 200 to 300 million crowns a year (£12.5-£19 million) set aside for research and development is going unspent. Often, it appears, the funds are not made available on time so that the planned innovation cannot be started. On the other hand, and particularly when the development programme has not been properly prepared, "random actions" occur, with funds being misappropriated and diverted to purposes "which have nothing to do with research and development". Sometimes, Rude Pravo noted, the funds have been spent on developments whose ultimate economic benefit has never been established.

This somewhat novel criticism found only a brief echo in Jakes' presentation to the party meeting: a call for the better use of the 19,000 million crowns ( $£ 1,200$ million) annually allotted to developing science and technology (4 per cent of the national income) to be concentrated on the "most decisive tasks" (including energy-saving technologies, microelectronics, the chemical industry and biotechnology).

Both Rude Pravo and Jakes suggested that most of the problems could be overcome with better labour discipline, but while the paper called for "the more consistent application of sanctions" to enterprises where there were shortcomings, Jakes concentrated on building up the research base with properly-motivated cadres, the need for better designers, technologists and development engineers, and the need to improve "moral" and financial incentives.

Vera Rich 